\title{
NEUTRON GENERATORS FOR SPENT FUEL ASSAY
}

\author{
Prepared for: \\ Office of Dismantlement and Transparency (NA-241) \\ U.S. Department of Energy \\ Funded by: \\ Next Generation Safeguard Initiative \\ U.S. Department of Energy
}

\begin{abstract}
Prepared by:
Bernhard Ludewigt

Accelerator and Fusion Research Division

Lawrence Berkeley National Laboratory

Berkeley, CA 94707, USA
\end{abstract}

December 30, 2010 


\section{DISCLAIMER}

This document was prepared as an account of work sponsored by the United States Government. While this document is believed to contain correct information, neither the United States Government nor any agency thereof, nor The Regents of the University of California, nor any of their employees, makes any warranty, express or implied, or assumes any legal responsibility for the accuracy, completeness, or usefulness of any information, apparatus, product, or process disclosed, or represents that its use would not infringe privately owned rights. Reference herein to any specific commercial product, process, or service by its trade name, trademark, manufacturer, or otherwise, does not necessarily constitute or imply its endorsement, recommendation, or favoring by the United States Government or any agency thereof, or The Regents of the University of California. The views and opinions of authors expressed herein do not necessarily state or reflect those of the United States Government or any agency thereof or The Regents of the University of California.

\section{ACKNOWLEDGMENTS}

This work was supported by the Next Generation Safeguards Initiative (NGSI), Office of Nonproliferation and International Security (NA-24), National Nuclear Security Administration, U.S. Department of Energy under Contract No. DE-AC02-05CH11231. 


\section{TABle OF Contents}

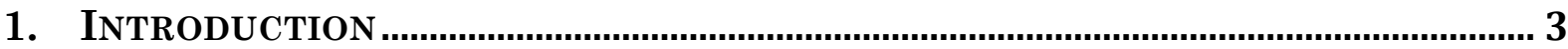

2. NEUTRON GENERATOR REQUIREMENTS............................................................... 3

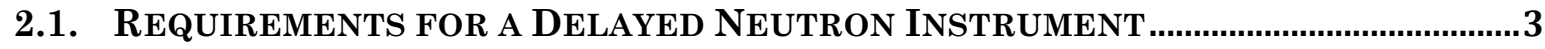

2.2. REQUIREMENTS FOR A DIFFERENTIAL DIE-AWAY INSTRUMENT ...........................5

2.3. REQUIREMENTS FOR A LEAD SLOWING DOWN SPECTROMETER ……......................5

3. NEUTRON GENERATION TECHNOLOGIES.............................................................. 5

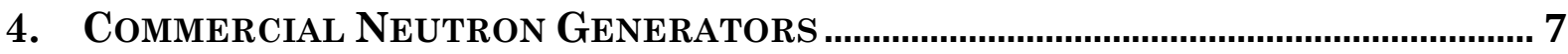

4.1. SOLID-TARGET NEUTRON GENERATORS .............................................................. 7

4.2. IEC NEUTRON GENERATORS ..............................................................................

5. OTHER NEUTRON GENERATOR/SOURCE OPTIONS.................................................... 9

5.1. ACCELERATOR-DRIVEN NEUTRON SOURCES...........................................................9

5.2. PHOTONEUTRON SOURCE................................................................................... 10

5.3. NON-COMMERCIAL DEVELOPMENT OF A HIGH-YIELD NEUTRON GENERATOR 11

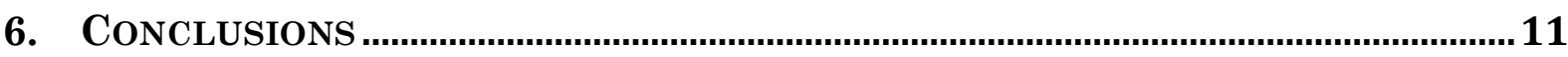

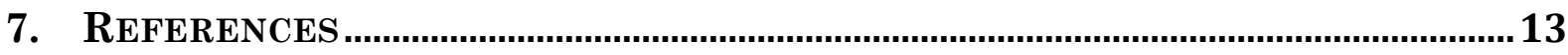




\section{INTRODUCTION}

The Next Generation Safeguards Initiative (NGSI) of the U.S. DOE has initiated a multi-lab/university collaboration to quantify the plutonium $(\mathrm{Pu})$ mass in, and detect the diversion of pins from, spent nuclear fuel (SNF) assemblies with non-destructive assay (NDA). The 14 NDA techniques being studied include several that require an external neutron source: Delayed Neutrons (DN), Differential Die-Away (DDA), Delayed Gammas (DG), and Lead Slowing-Down Spectroscopy (LSDS). This report provides a survey of currently available neutron sources and their underlying technology that may be suitable for NDA of SNF assemblies. The neutron sources considered here fall into two broad categories. The term "neutron generator" is commonly used for sealed devices that operate at relatively low acceleration voltages of less than $150 \mathrm{kV}$. Systems that employ an acceleration structure to produce ion beam energies from hundreds of $\mathrm{keV}$ to several $\mathrm{MeV}$, and that are pumped down to vacuum during operation, rather than being sealed units, are usually referred to as "accelerator-driven neutron sources."

Currently available neutron sources and future options are evaluated within the parameter space of the neutron generator/source requirements as currently understood and summarized in section 2. Applicable neutron source technologies are described in section 3. Commercially available neutron generators and other source options that could be made available in the near future with some further development and customization are discussed in sections 4 and 5, respectively. The pros and cons of the various options and possible ways forward are discussed in section 6 . Selection of the best approach must take a number of parameters into account including cost, size, lifetime, and power consumption, as well as neutron flux, neutron energy spectrum, and pulse structure that satisfy the requirements of the NDA instrument to be built.

\section{NeUtron Generator REQUiREMENTS}

External neutron sources or generators are needed for the delayed neutron, the delayed gamma, the differential die-away, and the lead slowing down spectroscopy techniques. Since the first three techniques will likely be incorporated into one instrument, it will be desirable to employ a neutron generator that satisfies the needs of all three techniques.

\subsection{REQUiREMENTS FOR A DELAYEd NEUTRON INSTRUMENT}

Figure 1 illustrates the design of a DN instrument. A deuterium-tritium (DT) neutron generator surrounded by moderating and reflecting material is located slightly more than $10 \mathrm{~cm}$ from the SNF assembly. Modeling results indicate that the required yield of $14 \mathrm{MeV}$ neutrons is $10^{11} \mathrm{n} / \mathrm{s}$. The neutron generator must be pulsed so that the irradiation of the assembly can be followed by a counting period during which the generator is off. However, with on and off times of the order of a second, the pulsing frequency can be very low. (Modeling has established a 2 s cycle: the generator is on for 
$0.9 \mathrm{~s}$ for the neutron irradiation; this period is followed by a $0.1 \mathrm{~s}$ pause and a $1 \mathrm{~s}$ counting time during which the neutron generator is off.)

It is likely that the neutron generator will need to produce $10^{11} \mathrm{n} / \mathrm{s}$ for a total of $\sim 500 \mathrm{~s}$ per SNF assembly for a DN system. A delayed neutron system will likely be employed in a reprocessing facility. For such a facility, measuring 15 assemblies a day is reasonable assumption. Hence, the generator would be on for $\sim 2$ hours a day. Assuming the facility operates $\sim 250$ days a year, the generator will run for 500 hours a year.

A softer neutron spectrum, i.e., lower neutron energies than $14 \mathrm{MeV}$ (possibly below the ${ }^{238} \mathrm{U}$ fission threshold), would reduce the ${ }^{238} \mathrm{U}$ fission rate and thus be potentially advantageous. However, initial studies have indicated that the performance of the instrument would not be drastically improved. In particular, no large differences have been found between using a DT source with $14 \mathrm{MeV}$ neutrons or a deuterium-deuterium (DD) source emitting $2.5 \mathrm{MeV}$ neutrons when the assay is made in water.

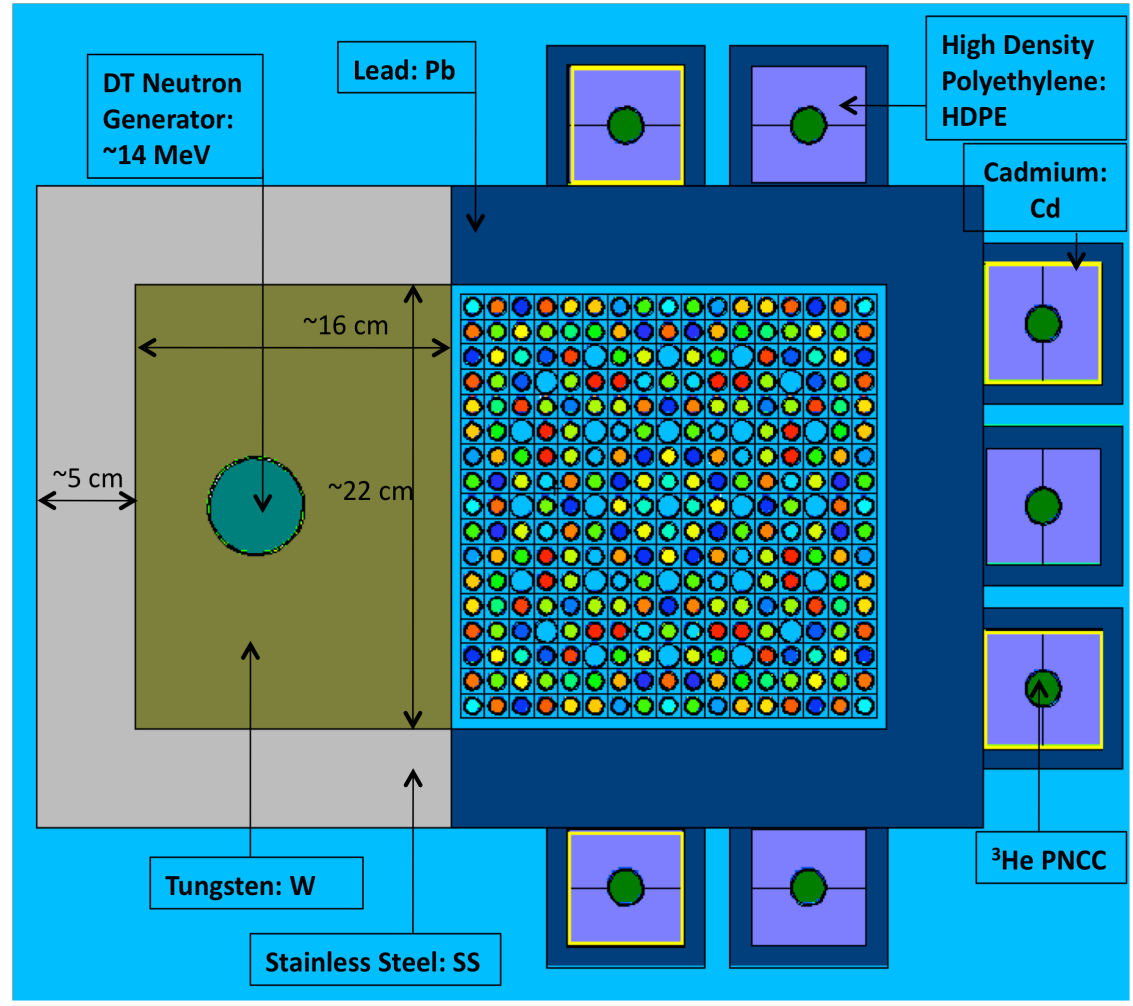

Figure 1. Illustration of DN instrument (from P. Blanc)

It is assumed here that a neutron generator that satisfies the requirements for a delayed neutron instrument also satisfies the needs of delayed gamma measurements, although, given the immaturity of the delayed gamma technique development, the neutron flux requirement could change by an order of magnitude. 


\subsection{REQUiREMENTS FOR A DIFFERENTIAL DiE-AWAy INSTRUMENT}

The arrangement for the DDA measurement as seen in figure 2 is quite similar to that of the DN instrument. The neutron generator is located on one side of the SNF assembly surrounded by moderating and reflecting materials. These measurements require short neutron pulses with lengths up to tens of microseconds, or at most a few hundred microseconds, at frequencies of about 100-200 Hz. A short fall-off time (in the microsecond range) is desired, although tens of microseconds may be acceptable. The required time-averaged neutron yield is expected to be one to two orders of magnitude lower than for delayed neutron measurements, i.e., $10^{10} \mathrm{n} / \mathrm{s}$ or less.

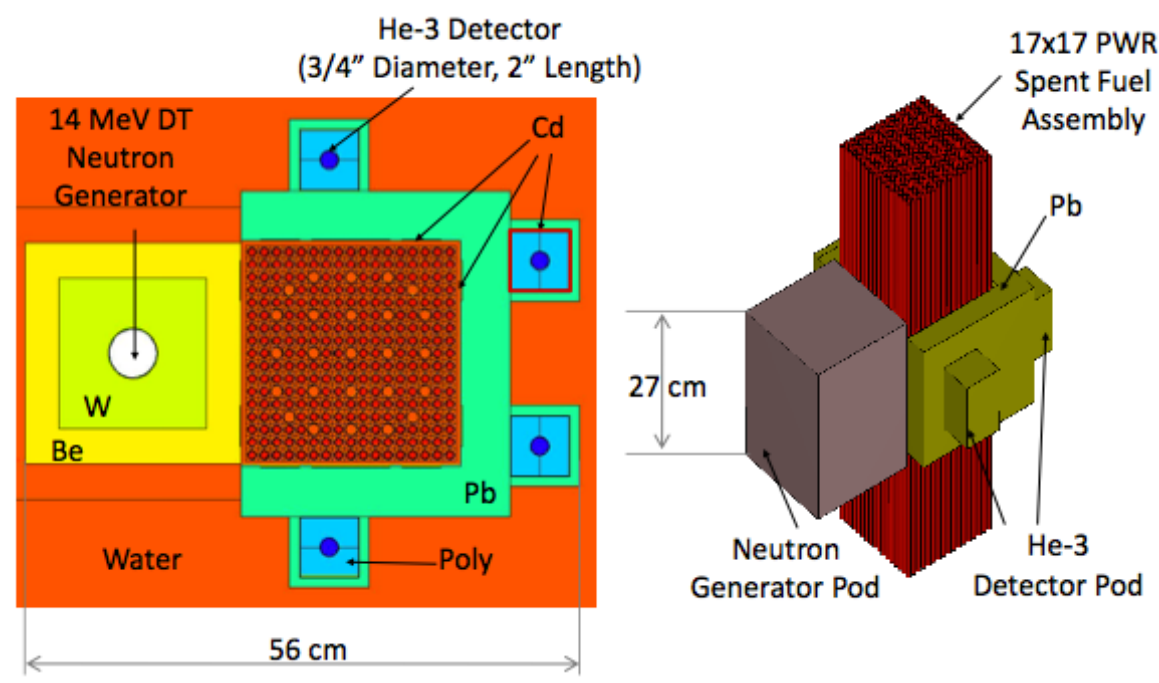

Figure 2. Illustration of the DDA instrument (from T. Lee)

\subsection{Requirements for a Lead Slowing Down Spectrometer}

The LSDS technique requires very short neutron pulses of about $1 \mu \mathrm{s}$ or less in duration at a repetition rate of about $100 \mathrm{~Hz}$. However, the required number of neutrons per pulse has not yet been established. Yields above $10^{8} \mathrm{n} /$ pulse or $10^{10} \mathrm{n} / \mathrm{s}$ will be difficult to provide, and new neutron source technology may be needed to reach the required output. Also, it is important to note that the neutron production target cannot be water-cooled, since any hydrogen in the system would spoil the measurement. Because the requirements have not been fully established, neutron generator/source options for this technique are only briefly discussed in this report.

\section{Neutron Generation Technologies}

The term "neutron generator" is commonly used for sealed devices that operate at relatively low acceleration voltages of less than $150 \mathrm{kV}$. Systems that employ an 
acceleration structure to produce ion beam energies from hundreds of $\mathrm{keV}$ to several $\mathrm{MeV}$ are usually referred to as "accelerator-driven neutron sources."

A variety of neutron generator and accelerator-driven neutron source technologies have been developed over the past decades. Most mature are neutron generators that employ a plasma ion source and a solid target containing deuterium and/or tritium. These generators are typically designed as sealed tubes that operate at ion acceleration voltages between $80 \mathrm{kV}$ and $150 \mathrm{kV}$. DT generators produce neutrons with energies of roughly $14 \mathrm{MeV}$, depending on emission angle and acceleration voltage. [1] The angular distribution is isotropic to within 10\%. Typical DT generators produce several times $10^{8}$ $\mathrm{n} / \mathrm{s}$. Some higher output devices and new developments are discussed in sections 4 and 5 . DD neutron yield is roughly two orders of magnitude lower than the DT yield. In DD mode the neutron energies vary between $2.1 \mathrm{MeV}$ and $2.9 \mathrm{MeV}$, depending on emission angle and acceleration voltage. The angular distribution peaks at forward and backward angles with the yield at $90^{\circ}$ being about $1 / 2$ the yield at $0^{\circ}$.

Neutron generators can be pulsed by switching the ion source, an extraction electrode, or the accelerating high voltage. Pulsing the high voltage may be necessary for techniques that require very low dark current, since it ensures that no ions are accelerated onto the target and no neutrons are produced. Generally, for these neutron generators the output decreases with operating time, and the tube lifetime is limited, due to the deterioration of targets and high-voltage insulation. Lifetimes for commercial generators range from thousands of hours for $\sim 10^{8} \mathrm{n} / \mathrm{s}$ DT generators to several hundred hours for the highest output devices.

An alternative neutron generator design uses a spark ion source instead of a Penning ion source. An advantage of these generators for the applications considered here is that they produce sub-microsecond pulses. A significant disadvantage is their much shorter lifetime.

A fundamentally different type of neutron generator that operates without a solid target is based on inertial electrostatic confinement (IEC). In these devices a high voltage is applied between a transparent grid cathode and a surrounding anode at ground potential. Positive ions generated in a discharge are accelerated to the cathode and pass through the grid into a plasma region where DD and/or DT fusion reactions occur. These generators, which can be operated pulsed or continuously, offer the prospect of very long lifetimes because they don't use a solid target. A disadvantage is the significantly lower power efficiency compared to conventional neutron generators. High neutron outputs of $\sim 10^{8} \mathrm{n} / \mathrm{s}$ and $10^{10} \mathrm{n} / \mathrm{s}$ in have been achieved in continuous DD and DT operation, respectively. [2,3] A more power-efficient design for a $10^{11} \mathrm{n} / \mathrm{s}$ DT device was developed at LANL but not built. [4] A more recent commercial effort is briefly summarized in section 4.2 .

A third type of neutron generator employs a plasma focus chamber. These devices produce short (10-30 ns), intense neutron pulses. However, their repetition rate is too low, and the number of pulses that can be delivered before the chamber has to be replaced is too low (on the order of 1000 pulses) for the applications considered here, so this type is mentioned only for completeness. [5]

Accelerator-driven neutron sources have been built for a variety of applications. These sources typically produce neutrons via the ${ }^{9} \mathrm{Be}(\mathrm{d}, \mathrm{n})^{10} \mathrm{~B},{ }^{7} \mathrm{Li}(\mathrm{p}, \mathrm{n})^{7} \mathrm{Be}$, or $\mathrm{D}(\mathrm{d}, \mathrm{n})^{3} \mathrm{He}$ reactions. The ion beams are typically accelerated to beam energies of several $\mathrm{MeV}$ by, 
for example, radio frequency quadrupole (RFQ) structures, sometimes coupled to a drift tube linac for reaching higher energies. These systems can readily provide the required $10^{11} \mathrm{n} / \mathrm{s}$ neutron yield and meet the pulsing requirements of the DN and DDA techniques. However, these sources are significantly larger, more complex, and more expensive than neutron generators.

Photoneutron sources are another alternative to neutron generators. In these sources an electron beam with an energy $>5 \mathrm{MeV}$ produces intense bremsstrahlung in a high-Z target. Neutrons are generated via photonuclear $(\gamma, \mathrm{n})$ reactions in a $\mathrm{D}_{2} \mathrm{O}$ or Be converter; these materials that have a low energy threshold (1.67 MeV for Be and 2.23 MeV for D). A system based on a $9 \mathrm{MeV}, 100 \mathrm{~mA}$ electron linac can produce a neutron yield exceeding $10^{11} \mathrm{n} / \mathrm{s}$ in short $(\mu \mathrm{s})$ pulses at rates up to several $100 \mathrm{~Hz}$ and is thus capable of satisfying DN and DDA instrument requirements.

\section{Commercial Neutron Generators}

\subsection{Solid-TARget NeUtron Generators}

Conventional, solid-target neutron generators are commercially available from several companies: Thermo-Scientific and Adelphi in the USA, EADS Sodern of France, and VNIIA of Russia.

Thermo Scientific

(http://www.thermoscientific.com/wps/portal/ts/products/catalog?categoryId=82242)

The highest-yield generator Thermo Scientific currently offers is the D711. It produces up to $2 \cdot 10^{10} \mathrm{n} / \mathrm{s}$ in continuous DT operation but has no pulsing capability. It may be possible to achieve $1 \mathrm{~s}$ "on" - $1 \mathrm{~s}$ "off" pulsing by switching the ion source, but this has not been tried and it is not known what on/off ratio may result for the neutron output. The lifetime of the D711 is specified as $1000 \mathrm{hrs}$ at $1 \cdot 10^{10} \mathrm{n} / \mathrm{s}$ or $500 \mathrm{hrs}$ at $2 \cdot 10^{10}$ $\mathrm{n} / \mathrm{s}$. The complete generator system is shown in figure 3 . The device in the back and on top is the generator head itself. It is 10 inches in diameter and the neutron production target is located $1.5 \mathrm{~cm}$ from the top. The larger vessel in the foreground is the highvoltage power supply. The control unit and coolers for target and ion source are seen on the right. The cost of the generator has been quoted as $\$ 325 \mathrm{k}$ installed.

Thermo Scientific's highest-yield pulsed generator is the P385. Its nominal DT yield is given as $3 \cdot 10^{8} \mathrm{n} / \mathrm{s}$ and its maximum yield as $5 \cdot 10^{8} \mathrm{n} / \mathrm{s}$. The generator can be pulsed at repetition rates from $250 \mathrm{~Hz}$ to $20 \mathrm{kHz}$ with duty factors ranging from $5 \%$ to $100 \%$. It provides a minimum pulse width of $5 \mu \mathrm{s}$ and a very short fall time of $0.5 \mu \mathrm{s}$. The accelerator head is 27 inches in length and 4 inches in diameter.

Thermo Scientific is currently developing a higher yield generator with a performance goal of $1 \cdot 10^{11} \mathrm{n} / \mathrm{s}$ in continuous operation. [6] The company expects this generator to be available within a year, or 9 months at the earliest. At least initially, this new generator will not be able to operate in pulsed mode, but this capability may be added later. 


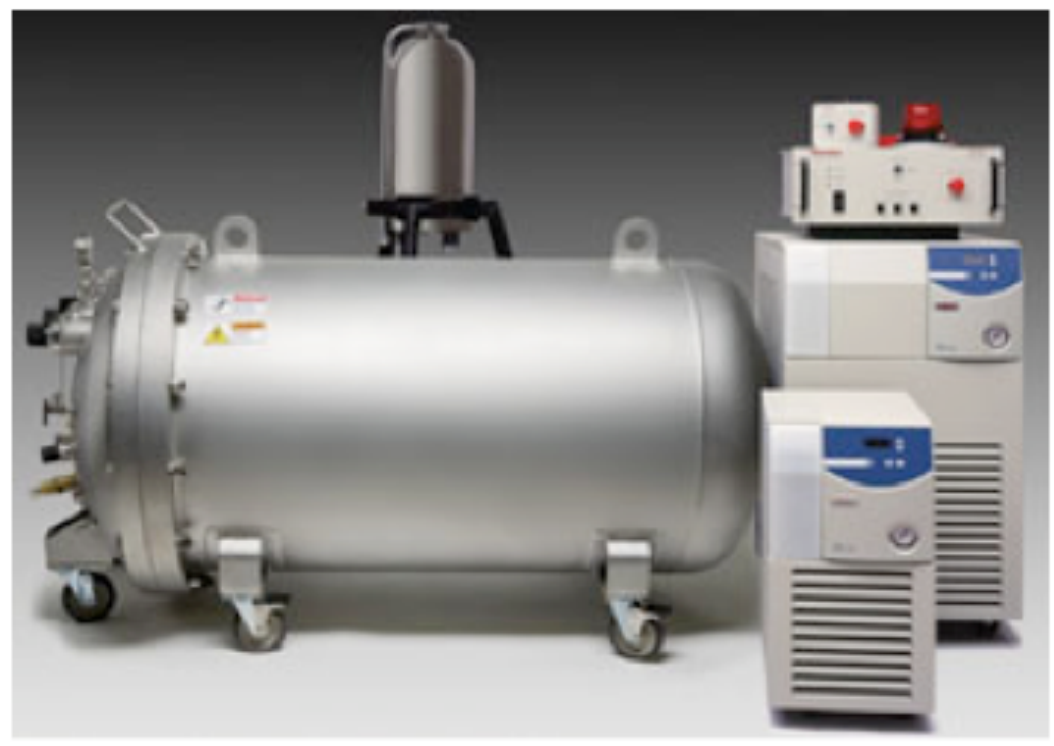

Figure 3. Thermo Scientific D711 neutron generator system.

Adelphi Technology, Inc.

(http://www.adelphitech.com/products.html)

Adelphi Technology currently offers DD neutron generators with neutron outputs of up to $4 \cdot 10^{9} \mathrm{n} / \mathrm{s}$. The company is now developing a sealed-tube device for DT operation and higher neutron yields of up to $1 \cdot 10^{11} \mathrm{n} / \mathrm{s}$. [7] The generator is based on LBNL technology and is expected to have a pulsing capability.

\section{EADS Sodern}

(http://www.sodern.com/site/FO/scripts/siteFO_contenu.php?noeu_id=45\&lang=EN)

EADS Sodern offers the GENIE 16 GT neutron generator with a maximum output of $2 \cdot 10^{8} \mathrm{n} / \mathrm{s}$ when operated in DT mode. The generator can be pulsed at rates from $10 \mathrm{~Hz}$ to $10 \mathrm{kHz}$, duty factors from 5 to $100 \%$, and rise and fall times shorter than $1.5 \mu \mathrm{s}$. The tube is $8 \mathrm{~cm}$ in diameter and $74 \mathrm{~cm}$ long.

The company also offers a high-output, pulsable neutron generator, the GENIE 35 . The high-yield version has special cooling provisions that allow it to operate up to a maximum average yield of $1 \cdot 10^{10} \mathrm{n} / \mathrm{s}$ DT. The generator can be pulsed similarly to the GENIE 16 with pulse rates of $10 \mathrm{~Hz}-10 \mathrm{kHz}$, nominal duty factor of 2.5-100\%, and rise and fall times of $<1.5 \mu \mathrm{s}$. The highest possible instantaneous neutron yield of $1 \cdot 10^{11} \mathrm{n} / \mathrm{s}$ may limit the average neutron flux in DDA applications, depending on pulse width and rate. The generator tube is $90 \mathrm{~cm}$ long and has a diameter of $15 \mathrm{~cm}$. The typical lifetime of the generator at the highest output is given as $>400 \mathrm{hrs}$. The lifetime increases quickly with decreasing neutron yield to $>2000 \mathrm{hrs}$ at $2 \cdot 10^{9} \mathrm{n} / \mathrm{s}$. The cost of the generator has been quoted as $\$ 220 \mathrm{k}$, not including installation and services. 
All-Russia Research Institute of Automatics, VNIIA

(http://www.vniia.ru/eng/ng/index.html)

VNIIA offers a variety of neutron generator options. These include generators using a Penning ion source similar to the ones offered by Thermo-Scientific and EADS Sodern. Their highest output generator of this type (ING-07) has a maximum yield of $1 \cdot 10^{9} \mathrm{n} / \mathrm{s}$ and can be pulsed up to $10 \mathrm{kHz}$ with a 20-100 $\mu$ s pulse width. The accelerator head is 19 $\mathrm{cm}$ in diameter and $44 \mathrm{~cm}$ long.

The company offers also solid-target generators equipped with a spark ion source. These devices produce short $(<1 \mu \mathrm{s})$, intense pulses at up to $100 \mathrm{~Hz}$ rates. The output of the largest device (ING-031) is specified as $2 \cdot 10^{8} \mathrm{n} /$ pulse for a yield of $2 \cdot 10^{10} \mathrm{n} / \mathrm{s}$. However, the lifetime of the ion source and generator head, when operating at $100 \mathrm{~Hz}$, is limited to 100 hours. The size of the acceleration head is $13 \mathrm{~cm}$ in diameter and $96 \mathrm{~cm}$ in length. The price of the ING-031 has been quoted as $\$ 57 \mathrm{k}$.

\subsection{IEC NEUTRON GENERATORS}

Neutron generators based on inertial electrostatic confinement are offered by NSDFusion GmbH. (http://www.nsd-fusion.com)

The company has developed a linear design that is suitable for low output devices and for high-yield DT generators. Tested prototypes have demonstrated operating lifetimes of several thousand hours and a neutron output of $2 \cdot 10^{7} \mathrm{n} / \mathrm{s}$ in DD operation.

The company has started to develop a high-end DT model for generating $1 \cdot 10^{11} \mathrm{n} / \mathrm{s}$ in DT mode. [8] The generator will be pulsed at $2 \mathrm{kHz}$ with fall times of less than $1 \mu \mathrm{s}$. The outside diameter of the generator tube has been specified as $14 \mathrm{~cm}$ and its overall length as $82 \mathrm{~cm}$. The length of the neutron producing region is $35 \mathrm{~cm}$. NSD-Fusion plans to have a fully qualified model within half a year. Power and cooling issues may be challenging.

\section{Other Neutron Generator/Source Options}

\subsection{ACCELERATOR-Driven NeUtron SourCes}

A line of accelerator-driven neutron sources, the LANSAR neutron generators, has been developed by AccSys Technology, Inc. (http://www.accsys.com/products/lansar.html).

These neutron sources are based on radio frequency quadrupole (RFQ) accelerators that accelerate deuteron or proton beams up to several $\mathrm{MeV}$ for the generation of neutrons in thick ${ }^{9} \mathrm{Be}$ or ${ }^{7} \mathrm{Li}$ targets. Most suitable for a DN/DG/DDA instrument is the use of the ${ }^{9} \mathrm{Be}(\mathrm{d}, \mathrm{n}){ }^{10} \mathrm{~B}$ reaction. This reaction gives the highest neutron output with a neutron energy spectrum that is fairly soft, peaking at around $2 \mathrm{MeV}$. The highest possible neutron energy is given by the sum of the deuteron beam energy and the $\mathrm{Q}$ value of the reaction of $4.3 \mathrm{MeV}$.

The technology is mature and AccSys offers several RFQ-based systems that have been built over the years. [9] Two systems that could be suitable for a DN/DDA 
instrument are the DL-2 and the DL-4. The DL-2 operates at frequencies up to $120 \mathrm{~Hz}$, a beam energy of $2.1 \mathrm{MeV}$, and a maximum beam current on target of 140 microampere. The corresponding maximum target yield is $1 \cdot 10^{11} \mathrm{n} / \mathrm{s}$. The DL-4 operates at a higher beam energy of $3.9 \mathrm{MeV}$ and has a higher maximum target current of $210 \mu \mathrm{A}$ resulting in a maximum target yield of $6 \cdot 10^{11} \mathrm{n} / \mathrm{s}$. The maximum pulse repetition rate of both models is $120 \mathrm{~Hz}$ and the pulse width is $30-120 \mu \mathrm{s}$. The length of the accelerator-based systems ranges from $2.5 \mathrm{~m}$ to $4 \mathrm{~m}$.

\subsection{Photoneutron Source}

Photoneutron sources have been used in research labs for many years and are now finding their way into cargo screening systems. However, such sources are currently not offered as stand-alone commercial products. Rapiscan Laboratories is developing an intense photoneutron source for nuclear material detection [10]. The neutron source is based on a Varian L2000, which is a $9 \mathrm{MeV}$ electron linac. A tungsten target is used to produce an intense bremsstrahlung beam that induces $(\gamma, n)$ reactions in a $\mathrm{D}_{2} \mathrm{O}$ or $\mathrm{Be}$ converter. The total conversion efficiency is $2 \cdot 10^{-4}$ neutrons per $9 \mathrm{MeV}$ electron, which results in $\mathrm{a}>1 \cdot 10^{11} \mathrm{n} / \mathrm{s}$ yield for the $100 \mu \mathrm{A}$ beam current the linac can deliver. The neutron yield is roughly the same for both converters but the neutron spectrum for the $\mathrm{D}_{2} \mathrm{O}$ is somewhat softer than that for the Be. The thickness of the converter is roughly 10 $\mathrm{cm}$. (The thicker the converter, the higher the neutron yield and the softer the neutron spectrum.)

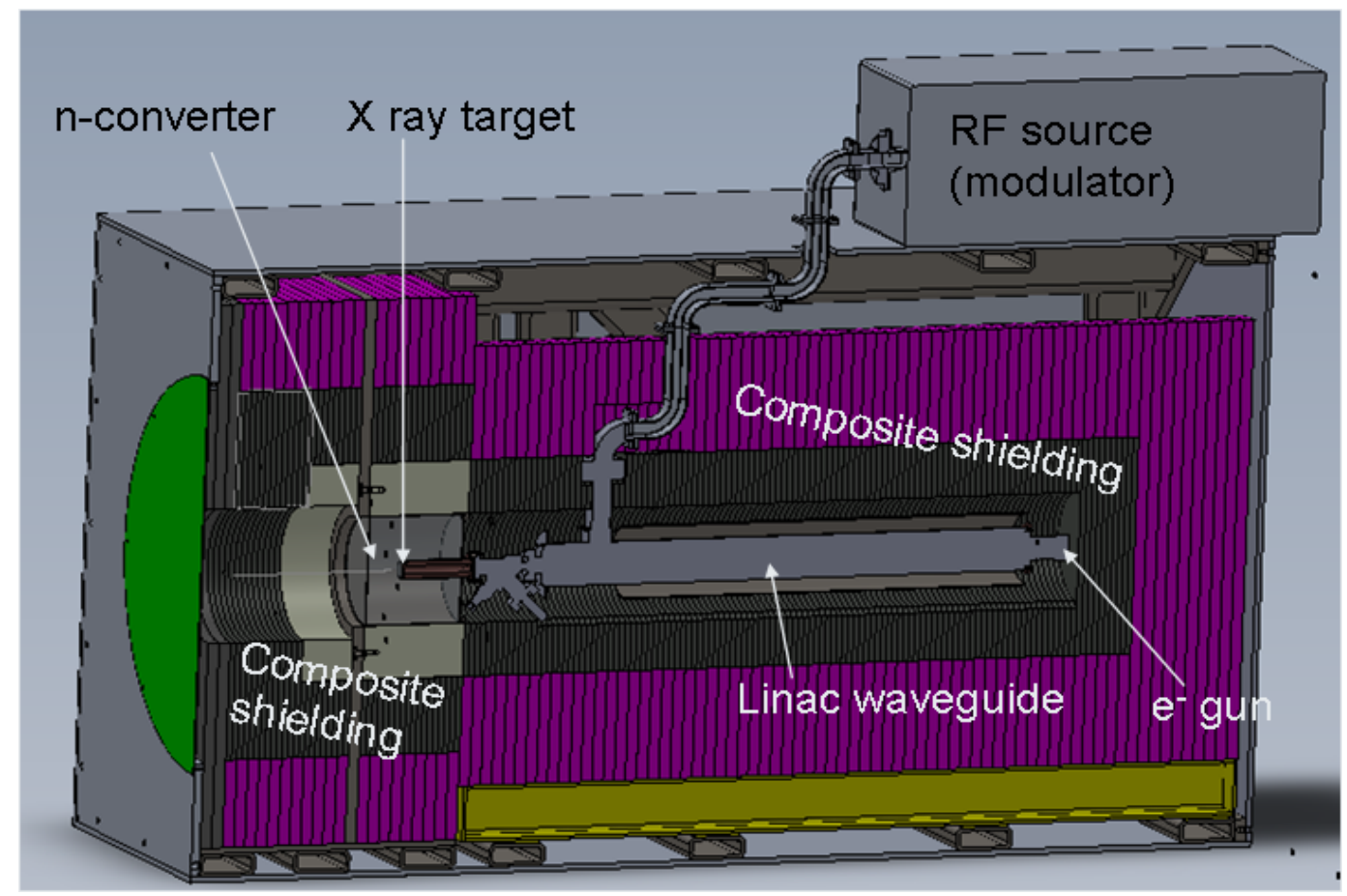

Figure 4. Rapiscan Laboratories' photoneutron source assembly. The length of the assembly is about $2.5 \mathrm{~m}$. 
A $6-\mathrm{MeV}$ linac would give one-third the neutron output. Either the 6- or the 9-MeV linacs would generate 1-2 $\mu$ s long pulses at rates up to $300 \mathrm{~Hz}$. This pulse structure is well suited for DDA measurements. The short pulse length makes such a photoneutron source a candidate for an LSDS instrument as well, provided the neutron output is sufficiently high and the neutron energy spectrum is suitable.

\subsection{NON-COMMERCIAL DEVElopMENT OF A High-YIELD NEUTRON GENERATOR}

High-output DD generators developed at the Lawrence Berkeley National Laboratory (LBNL), based on a novel coaxial geometry, have produced neutron yields of several times $10^{9} \mathrm{n} / \mathrm{s}$ [11]. That concept was extended to the design of a larger coaxial DD generator for producing $1 \cdot 10^{11} \mathrm{n} / \mathrm{s}$. That device was built but never tested, and more R\&D would be needed to make it operational. Also, its neutron-producing coaxial target is rather large, and power and cooling requirements are very high.

A more promising generator for a DN/DDA instrument may be a sealed-tube DT generator currently under development at LBNL. In this design a $100 \mathrm{~mA}$ beam is extracted from a plasma ion source and accelerated onto a solid target by a $100 \mathrm{kV}$ target bias voltage. The generator tube is about $25 \mathrm{~cm}$ in diameter and $100 \mathrm{~cm}$ long. The design neutron yield is $5 \cdot 10^{11} \mathrm{n} / \mathrm{s}$ when operated continuously [12]. The generator is equipped with an extraction electrode that can achieve the relatively fast pulsing needed for DDA measurements. The much slower pulsing for DN measurements may be accomplished by switching the high voltage. Initial testing uncovered weaknesses in high-voltage holding that prevented operation at full voltage and current. This has since been corrected. In addition, the original radiofrequency-driven ion source has been replaced by a microwave ion source to achieve more reliable operation. [13] The reassembled generator is now ready for further testing.

\section{Conclusions}

There are a variety of options based on different technologies for obtaining a neutron source that can meet the requirements of a delayed neutron/gamma and differential dieaway instrument. These options include sealed-tube neutron generators as well as larger, accelerator-driven systems.

There is currently no neutron generator commercially available that can deliver $1 \cdot 10^{11}$ $\mathrm{n} / \mathrm{s}$ as needed for DN measurements. The highest output device reaches a yield of $2 \cdot 10^{10}$ $\mathrm{n} / \mathrm{s}$. This generator from Thermo-Scientific has been sold and used for many years but it cannot be pulsed. EADS SODERN offers a $1 \cdot 10^{10} \mathrm{n} / \mathrm{s}$ generator that can be pulsed and may be suitable for a DDA instrument. VNIIA offers a generator that utilizes a spark ion source for producing short neutron pulses; however, its lifetime is severely limited.

At least three companies are currently developing generators with the goal to provide a $1 \cdot 10^{11} \mathrm{n} / \mathrm{s}$ DT neutron yield. Thermo-Scientific expects its new generator to be available within less than a year. At least initially, this new generator will not be able to operate in pulsed mode but this capability may be added later. Adelphi Technologies is developing a generator that is based on the LBNL design and is expected to provide a 
pulsing capability. NSD-Fusion plans to have a fully-qualified IEC generator in half a year that would meet the DN/DDA yield and pulsing requirements. Since it is difficult to predict how successful and on schedule these companies will be, the status of these new generator developments, and the capabilities of the companies to deliver a device that meets specifications, should be reassessed at appropriate decision points in the instrument design and neutron generator selection process.

Completion of the LBNL high-yield, sealed-tube generator, which would satisfy DN and DDA requirements, could be a viable alternative in case the commercial developments are not successful in meeting the requirements in time.

One might consider combining several of VNIIA's ING-031 generators to meet the requirement of a particular instrument. Given the relatively short lifetime of these tubes (100 hrs), the practicality of this approach would depend on overall operating times and tube replacement costs and may not be viable in the context of a reprocessing facility.

The EADS Sodern GENIE35 generator, with its relatively high yield and pulsing capability, may be suitable for the DDA measurements.

Two neutron source options based on mature technologies now available can fully satisfy the DN and DDA requirements. AccSys Technologies offers accelerator-driven neutron sources (models DL-2 or DL-4) that can provide the required neutron yield and pulsing capabilities. The disadvantages of such a source are larger size, complexity, and higher cost, which may be in the $\$ 1 \mathrm{M}$ range (not a company quote).

The second option is a photoneutron source as assembled by Rapiscan Laboratories. This source is based on mature electron linac technology, which is used, for example, in clinical radiation therapy machines, and reliable performance can be expected over a long period of time. However, the cost would be relatively high due to the cost of the electron linac, which is roughly $\$ 750 \mathrm{k}$ for a $9 \mathrm{MeV}, 100 \mu \mathrm{A}$ accelerator and $\$ 500 \mathrm{k}$ for a 6 $\mathrm{MeV}$ machine. Design and optimization of the $\mathrm{D}_{2} \mathrm{O}$ or Be photoneutron converter would need to be integrated with the design of the DN/DDA instrument. Also, integration of either of these larger neutron sources - the accelerator-driven neutron source or the photoneutron source - into a SNF assembly measurement facility would need to be studied further.

An LSDS instrument likely poses the most demanding neutron generator/source requirements. Currently, generators that utilize spark ion sources can produce $1 \mu \mathrm{s}$ pulses, but the neutron output of $1 \cdot 10^{10} \mathrm{n} / \mathrm{s}$ may be one or more orders of magnitude too low. Photoneutron sources may be an alternative, given their capability to generate 1-2 $\mu \mathrm{s}$ long pulses and neutron yields exceeding $1 \cdot 10^{11} \mathrm{n} / \mathrm{s}$ depending on beam current and energy of the electron linac.

A wide range of considerations will play a role in selecting the most suitable neutron source for a particular instrument. Selection criteria include: neutron yield, pulsing capabilities, cost, size, reliability, and integration into the DN/DDA/DG or LSDS instrument. In the first phase of experimental development, the range of source capabilities and flexibility may be more important than reliability and cost. Thus, one may want to consider using a different generator/source for the early phase than for later prototyping of a deployable instrument. 


\section{REFERENCES}

[1] CRC Handbook of Fast Neutron Generators, author J. Csikai, CRC Press Inc., 1987.

[2] R.L. Hirsh, J. Appl. Phys. 38 (1967) 4522.

[3] R.P. Ashley et al., Fusion Technol. 39 (2001) 546.

[4] M. M. Pickrell, Final Report, U.S. Department of Energy, Development of a High Fluence Neutron Source for Nondestructive Characterization of Nuclear Waste, 1999.

[5] Comparative Characteristics of Four Small Dense Plasma Focus Devices, A.V. Dubrovsky et al., AIP Conference Proceedings, CP996, Plasma and Fusion Science, p. 103-107, 2008.

[6] Jim Simpson (Thermo-Scientific), private communication.

[7] Melvin Piestrup (Adelphi Technology), private communication.

[8] John Sved (NSD-Fusion), private communication.

[9] http://www.accsys.com/downloads/Lansar_Brochure.pdf

[10] Intense Photoneutron Sources for Nuclear Material Detection, Tsahi Gozani, Timothy Shaw, and Michael King, Proceedings of the $21^{\text {st }}$ International Conference on the Application of Accelerators in Research and Industry, CAARI 2010, Fort Worth, TX, August 8-13, 2010.

[11] D-D Neutron Generator Development at LBNL, J. Reijonen et al., Applied Radiation and Isotopes 63, 757-763, 2005.

[12] High-yield DT Neutron Generator, B.A. Ludewigt et al., Nuclear Instruments and Methods in Physics Research B261, 830-834, 2007.

[13] A Permanent-Magnet Microwave Ion Source for a Compact High-Yield Neutron Generator, O. Waldmann and B. Ludewigt, Proceedings of the $21^{\text {st }}$ International Conference on the Application of Accelerators in Research and Industry, CAARI 2010, Fort Worth, TX, August 8-13, 2010. 